\title{
Comparison of the standing balance between pole vaulters and soccer players in preseason and postseason
}

\author{
Katarzyna Dmitruk ${ }^{1 \mathrm{ACD}}$, Małgorzata Gałązka ${ }^{1 \mathrm{~B}}$, Mirosława Cieślicka ${ }^{1 \mathrm{BD}}$, Dariusz Soszyński ${ }^{1,2 \mathrm{~A}}$, Robert Stępniak ${ }^{3 \mathrm{~B}}$, \\ Mariusz Klimczyk ${ }^{3 \mathrm{BC}}$, Sergii S. Iermakov ${ }^{4 \mathrm{BD}}$ \\ ${ }^{1}$ Collegium Medicum in Bydgoszcz, Nicolaus Copernicus University in Toruń, Poland \\ ${ }^{2}$ Universitas Opoliensis Institute of Medicine, Poland \\ ${ }^{3}$ Kazimierz Wielki University in Bydgoszcz, Poland \\ ${ }^{4}$ Gdansk University of Physical Education and Sport, Poland
}

Authors' Contribution: A - Study design; B - Data collection; C - Statistical analysis; D - Manuscript Preparation; E - Funds Collection.

\begin{abstract}
Purpose: $\quad$ Static is crucial in the maintaining the position of the body's center of gravity vertically over the base of support. Many sport disciplines require effective balance system. However, the efficiency of the system differs based on the sport discipline. The aim of the study was to examine balance system efficiency in pole vaulters and soccer players. Additionally, the analysis of pre and postseason balance system efficiency was performed in pole vaulters and soccer players as well.

Material: $\quad$ To asses static balance system efficiency five pole vaulters and six soccer players were examined. A balance platform was used for open eyes test, close eyes test and biofeedback test. During the tests displacements of the center of pressure (COP) and calculates parameters such as: sway area in $\mathrm{mm}^{2}(P)$, mean total length in $\mathrm{mm}(L)$, path length in antero-posterior plane in $\mathrm{mm}\left(L_{A-P}\right)$, path length in medio-lateral plane in $\mathrm{mm}\left(L_{M-L}\right)$ and coordination in $\%(C)$ were obtained.

Results: $\quad$ Pole volunteers displayed better static balance and coordination compared to soccer players both in postseason and preseason time. Static balance and coordination were better in preseason compared to postseason time in pole vaulters. The observed differences were not statistically significant. Soccer players exhibited lower balance scores (statistically significant) in preseason compared to postseason. The eyes closure resulted in increased values of both total sway length, sway length in AP plane and sway length in ML plane both in postseason and preseason time for both groups of athletes. Intercondition significance was assessed only for total sway length and sway length in AP plane in pole vaulters in postseason time.

Conclusions: Pole vaulters and soccer players did not differ in terms of static balance, but our results point toward an overall tendency for pole vaulters to exhibit better standing balance and visual-motor coordination compared soccer players.

Keywords: $\quad$ static balance, posturography, pole vaulters, soccer players
\end{abstract}

\author{
Abbreviations \\ COG- body's center of gravity \\ BOS- base of support \\ VMI- visual-motor coordination \\ COP- center of pressure \\ P- sway area \\ L- mean total length \\ $\mathrm{L}_{\mathrm{A}-\mathrm{P}}$ - path length in antero-posterior plane \\ $\mathrm{L}_{\mathrm{A}-\mathrm{P}}$ - path length in medio-lateral plane \\ C- coordination \\ ET1- open eyes test \\ ET2- closed eyes test \\ ET3-biofeedback test \\ AP-anterio-posterior plane \\ ML- medio-lateral plane \\ ACL-anterior cruciate ligament
}

\section{Introduction}

Balance is the process of maintaining the position

(c) Katarzyna Dmitruk, Małgorzata Gałązka, Mirosława Cieślicka,

Dariusz Soszyński, Robert Stępniak, Mariusz Klimczyk,

Sergii S. lermakov, 2020

doi:10.15561/20755279.2020.0204 of the body's center of gravity (COG) vertically over the base of support (BOS) [1]. Both static and dynamic balance involves some structures of the central nervous system to integrate sensory information from visual, vestibular, proprioceptive and exteroceptive receptors in the centers of analysis. These structures are located at different levels of the central nervous system: the spinal cord, basal ganglia, cerebellum and cerebral cortex. The cerebellum, brainstem and frontal lobe are together involved in control of visual- motor coordination (VMI). VMI is able to integrate visual input with motor output which ensures a coordinated movement.

Balance is a key component to athletic activities like soccer, gymnastics, running [2-5] and pole vault. The necessary visual components for a pole vaulter include: dynamic visual skills, peripheral vision, dynamic depth perception to judge the distance from the pole tip to the box, visual tracking, contrast sensitivity and depth perception. Therefore training programme in pole vaulters is limited not only at physical preparation but also includes exercises for improving the time-space orientation and might be important for increasing the balance control. In soccer players, coordination depends mostly on a sense of 
timing, speed and flight path of the ball and then is used by the players in specific skills such as controlling, dribbling and passing. For this reason the typical soccer training typically involves a high degree of focus on the external surrounding, i.e. the ball or/and other players. The most important elements able to influence coordination are power, speed, reaction time and endurance.

The pole vault is a sport where the successful competitor must combine a high level of athletic prowess with the development of unerring technique. Specific training for this athletic discipline enables the development of coordination skills, orientation in time and space, flexibility and agility. The world-class pole vaulter often possess also sprinting capability similar to that of elite sprinter. The speed on the runway is strongly related to amount of energy which is directed into the pole and then transferred into the vertical movement of the athlete to the bar. Therefore, the pole vaulter must be both a good sprinter and gymnast. Moreover, the vaulter should also have a strong upper body, particularly shoulders, to generate additional force on the push of the pole into the ground on take off. The vaulter must also be extremely coordinated, able to contort their body in midair on the approach to the bar.

Soccer players range in activity from walking to jogging and sprinting. It has been suggested that about $2 / 3$ of the total distance (from 4.5 to 9.5 miles in one game) is done in the walking and jogging states, leaving $1 / 3$ to be done in running and sprinting states. Soccer players frequently support their body mass on one leg when kicking a ball. Therefore, the aim of the strength training for soccer players is the improvement of legs strength, especially in the quadriceps to help stabilize the knee joint [6].

Both pole vaulter and soccer player require excellent standing balance. Pole vaulters are expected to be extremely aware regarding the placement and motion of their body. This type of balance is clearly different than soccer players. Soccer players have to maintain balance during the run with low or high speed when they rapidly change direction and kick the ball standing on the one foot. Therefore, soccer players have been mostly compared with other athletes such as gymnasts [3, 7], modern and ballet dancers [5], swimmers [7, 8] and others.

Hypothesis. We hypothesize that pole vaulters have better standing balance than soccer players due to great awareness of body position in space.

Purpose. Since, up to now there is no experimental data showing balance system efficiency, the aim of the study was to examine this kind of sense in pole vaulters. Because there is significant improvement in balance system due to training we analyzed the balance system of athletes in preseason and postseason. Additionally, we compared balance control between pole vaulters and soccer players both in preseason and postseason.

\section{Materials and Methods}

Participants

Five pole vaulters and six soccer players (all male; mean age $18.2 \pm 1.3$, ranged from 17 to 20 years, and $18.0 \pm 0.7,17$ to 19 years, respectively) were recruited. The pole vaulters were members of the Junior National Team. They practiced pole vault about six years. A small number of athletes results from the small number of young individuals practicing this kind of sports discipline. The soccer players group consist of the participants practicing that discipline about 10 years. They were recruited from The District Junior Football League. All subjects had no history of neurological, muscular and metabolic diseases. In addition, they did not drink alcohol and not take any drugs disturbing locomotor functions. All participants were examined two times: in April- time just before start of competitions season (preseason) and in October- at the end of participation in competitions season (postseason). The study was approved by the Ethics Commision of The Ludwik Rydygier Collegium Medicum in Bydgoszcz (Poland).

\section{Research Design}

A balance platform (PROMED, Poland) was used for the assessment of the static postural control. This diagnostic system computes displacements of the center of pressure (COP) and calculates parameters such as: sway area in $\mathrm{mm}^{2}(P)$, mean total length in $\mathrm{mm}(L)$, path length in antero-posterior plane in $\mathrm{mm}\left(L_{A-P}\right)$, path length in medio-lateral plane in $\mathrm{mm}\left(L_{M-L}\right)$ and coordination in $\%(C)$.

Three different test conditions were used for bipedal balance assessment: open eyes (ET1), closed eyes test (ET2) and biofeedback test (ET3). In all conditions, the subjects stood for $32 \mathrm{~s}$ while COP data were collected. One practice trial was allowed before the beginning of data collection and a 3 minutes seated rest period was provided between trials. Force measurements were taken at sampling rate of 40 per second. Test circumstances (e.g. noise, illumination) were in accordance with recommendations for posturographic testing. All tests were performed in the morning hours. The subject standing without shoes on the platform (the angle between feet of approximately $30^{\circ}$ and the distance between the heels of $2 \mathrm{~cm}$ ) was asked to keep upright posture with his/her arms along the trunk. During ET1 the subject is asked to look forward maintaining described above body position. While ET2 the visual information is eliminated due to eyes closure. In the biofeedback test at eye level, the monitor was placed two meters from the subject. The participant was asked to keep the cursor indicating the current position of the COP in the square located in the center of the screen.

\section{Statistical Analysis.}

All analyses were conducted using statistical software STATISTICA $10.0\left(\right.$ StatSoft $\left.^{\circledR}\right)$. Analyzed variables were normally distributed and therefore parametric statistics was used for statistical analysis. Quantitative variables were described with means and standard deviations (S.D.). The significance of differences between groups as well as between data collection time (pre- and postseason) was tested using Student $t$-test. The level of significance for all tests was set at $p<0.05$. 


\section{Results}

Demographic data of athletes are presented in Table 1.

Pole vaulters were significantly taller than soccer players both in preseason and postseason. Soccer players weighed more compared to pole vaulters in preseason as well as postseason time but statistically significant differences were observed only in postseason.

The posturographic parameters for pole vaulters and soccer players in preseason and postseason time are shown in Table 2.

Mean scores of the sway area, mean total length, path length in AP plane in ET1, ET2 and ET3 were lower in pole vaulters compared to soccer players in preseason time. The observed differences were not statistical significant.
Coordination parameter was higher in pole vaulters comparing to soccer players but it was no significant in common with postseason time. Moreover, mean scores of the sway area, mean total length, path length in anteroposterior plane, path length in medio-lateral plane in ET1, ET2 and ET3 were lower in pole vaulters compared to soccer players in postseason. Again, differences did not reach statistical significance.

The eyes closure resulted in increased values of both mean total length, path length in AP plane and path length in medio-lateral plane both in preseason and postseason for both groups of athletes. Intercondition significance was assessed only for mean total length $(p=0.049)$ and path length in antero-posterior plane $(p=0.032)$ in pole

Table 1. Demographics of the athletes

\begin{tabular}{|c|c|c|c|c|c|c|}
\hline \multirow[b]{2}{*}{ Variable } & \multicolumn{2}{|c|}{ Pole vaulters $(n=5)$} & \multicolumn{4}{|c|}{ Soccer players $(n=6)$} \\
\hline & Preseason & Postseason & Preseason & Postseason & $\begin{array}{l}\text { Preseason } \\
\text { p-Value }\end{array}$ & $\begin{array}{l}\text { Postseason } \\
\text { p-Value }\end{array}$ \\
\hline Age (years) & $19.2 \pm 1.3$ & $18.2 \pm 1.3$ & $19 \pm 0.7$ & $18 \pm 0.7$ & 0.38 & 0.38 \\
\hline Height $(\mathrm{cm})$ & $186 \pm 3.2$ & $185 \pm 3.6$ & $181.2 \pm 2.5$ & $180.5 \pm 2.9$ & $0.01 *$ & $0.03 *$ \\
\hline Weight (kg) & $74 \pm 4.2$ & $71.2 \pm 3.6$ & $77.5 \pm 3.1$ & $76.7 \pm 3.6$ & 0.07 & $0.02 *$ \\
\hline
\end{tabular}

Note. Data represent mean \pm S.D. with groups compared by the Student t-test; $*$ Statistically significant.

Table 2. Sway area, mean total length, path length in AP plane, path length in ML plane in pole vaulters and soccer players

\begin{tabular}{|c|c|c|c|c|c|c|c|}
\hline Variable & Test & $\begin{array}{l}\text { Preseason } \\
\text { Pole vaulters } \\
(=5) \\
\text { Mean } \pm \text { S.D. }\end{array}$ & $\begin{array}{l}\text { Soccer players } \\
(n=6) \\
\text { Mean } \pm \text { S.D. }\end{array}$ & $p$-Value & $\begin{array}{l}\text { Postseason } \\
\text { Pole vaulters } \\
(n=5) \\
\text { Mean } \pm \text { S.D. }\end{array}$ & $\begin{array}{l}\text { Soccer } \\
\text { players }(n=6) \\
\text { Mean } \pm \text { S.D. }\end{array}$ & $p$-Value \\
\hline \multirow{3}{*}{$P$} & ET1 & $487,6 \pm 111.2$ & $655,7 \pm 419.5$ & 0.38 & $544.4 \pm 188.9$ & $595.5 \pm 110.5$ & 0.59 \\
\hline & ET2 & $521.0 \pm 114.2$ & $571.2 \pm 208.6$ & 0.64 & $526.2 \pm 78.4$ & $620.5 \pm 193.3$ & 0.34 \\
\hline & ET3 & $363.2 \pm 91.5$ & $468.3 \pm 142.7$ & 0.19 & $455.4 \pm 117.6$ & $580.7 \pm 231.9$ & 0.30 \\
\hline \multirow{3}{*}{$L$} & ET1 & $682.6 \pm 44.4$ & $692.7 \pm 89.2$ & 0.82 & $704.8 \pm 39.9$ & $739.7 \pm 96.6$ & 0.47 \\
\hline & ET2 & $695.0 \pm 31.1$ & $698.2 \pm 67.2$ & 0.93 & $736.8 \pm 59.1$ & $757.5 \pm 97,2$ & 0.69 \\
\hline & ET3 & $679.4 \pm 32.2$ & $686.7 \pm 72.7$ & 0.84 & $722.2 \pm 61.6$ & $770.7 \pm 75.4$ & 0.28 \\
\hline \multirow{3}{*}{${ }_{L A-} \mathrm{P}$} & ET1 & $443.2 \pm 27.9$ & $458.3 \pm 78.7$ & 0.69 & $456.2 \pm 38.1$ & $483.0 \pm 64.2$ & 0.43 \\
\hline & ET2 & $455.6 \pm 25.5$ & $463.7 \pm 47.9$ & 0.74 & $484.0 \pm 44.1$ & $502.0 \pm 70.1$ & 0.63 \\
\hline & ET3 & $441.6 \pm 22.4$ & $451.3 \pm 54.8$ & 0.72 & $475.0 \pm 53.5$ & $509.8 \pm 59.4$ & 0.34 \\
\hline \multirow{3}{*}{$L_{M-L}$} & ET1 & $422.4 \pm 31.2$ & $418.5 \pm 34.2$ & 0.85 & $438.2 \pm 17.8$ & $456.8 \pm 57.6$ & 0.48 \\
\hline & ET2 & $428.8 \pm 20.1$ & $423.0 \pm 40.4$ & 0.78 & $449.0 \pm 34.0$ & $462.3 \pm 57.3$ & 0.66 \\
\hline & ET3 & $422.0 \pm 21.5$ & $420.8 \pm 42.5$ & 0.96 & $440.8 \pm 27.8$ & $472.0 \pm 44.4$ & 0.21 \\
\hline C & ET3 & $90.0 \pm 8.2$ & $82.4 \pm 9.6$ & 0.19 & $86.5 \pm 9.6$ & $82.0 \pm 13.8$ & 0.56 \\
\hline
\end{tabular}

Table 3. Influence of vision on balance control in pole vaulters and soccer players

\begin{tabular}{lllll}
\hline Variable & $\begin{array}{l}\text { Pole vaulters }(\mathbf{n}=5) \\
\text { Preseason } \\
\text { p-Value }\end{array}$ & $\begin{array}{l}\text { Postseason } \\
\mathbf{p} \text {-Value }\end{array}$ & $\begin{array}{l}\text { Soccer players }(\mathbf{n}=6) \\
\text { Preseason } \\
\text { p-Value }\end{array}$ & $\begin{array}{l}\text { Postseason } \\
\text { p-Value }\end{array}$ \\
\hline Sway area & & & & \\
Mean total length & 0,3627 & 0,4299 & 0,2017 & 0,3050 \\
Path length in AP plane & 0,2849 & $0,0495^{*}$ & 0,4110 & 0,1277 \\
Path length in ML plane & 0,2869 & $0,0323^{*}$ & 0,4056 & 0,0971 \\
\hline
\end{tabular}

Note. Data represent mean \pm S.D. with groups compared by the Student t-test. * Statistically significant. 


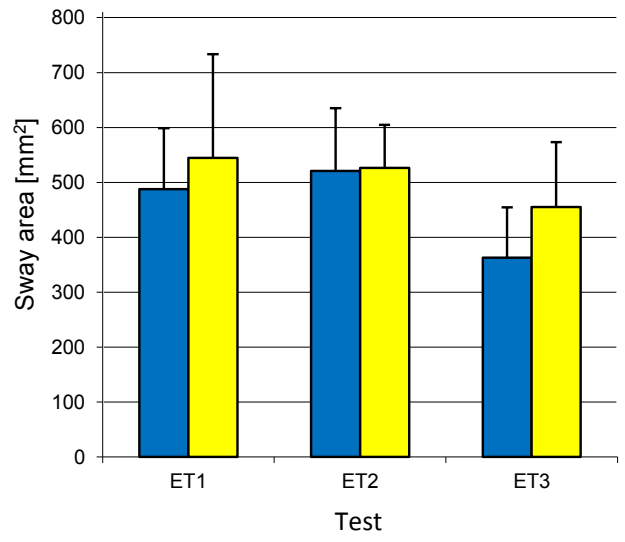

a

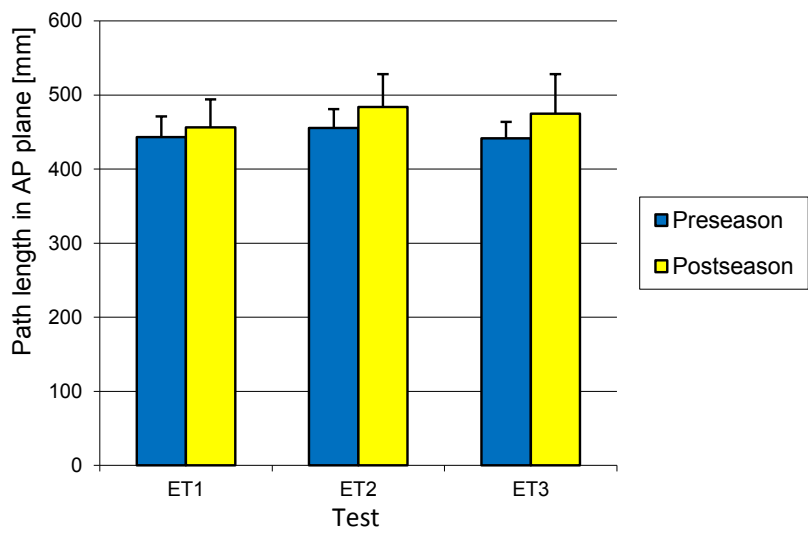

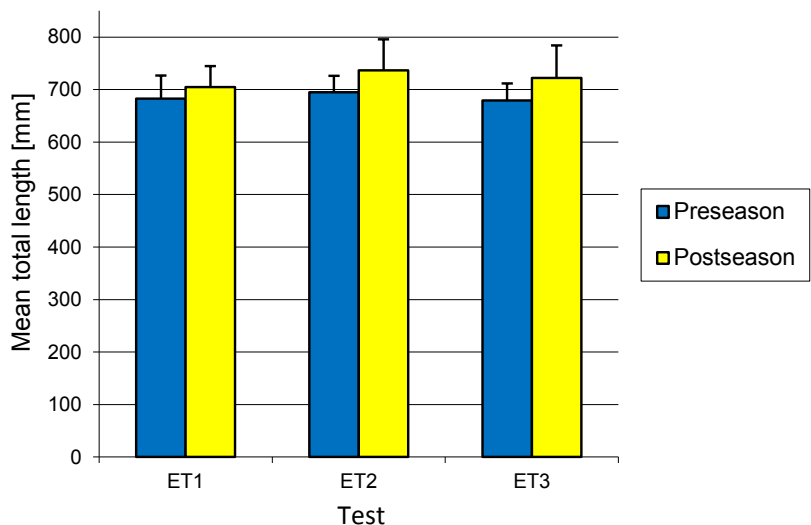

b

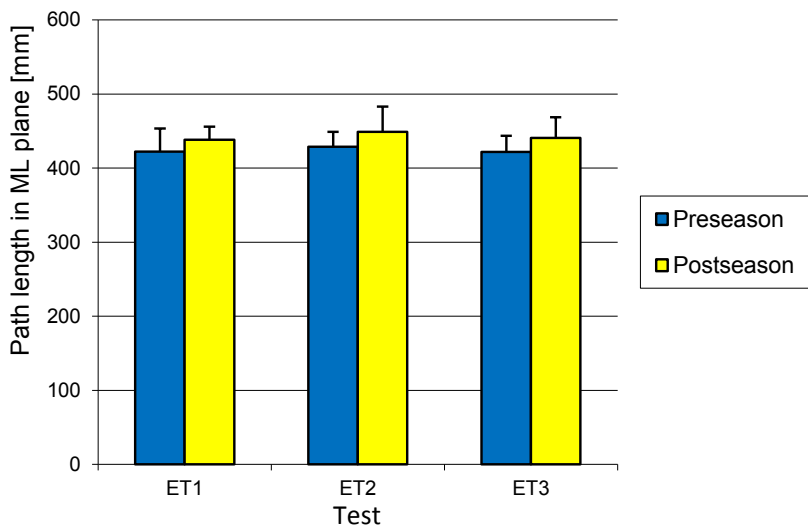

d

Figure 1. Group mean values ( \pm S.D.) of sway area, total length of stabilogram, length of stabilogram in sagittal plane and length of stabilogram in frontal plane in pole vaulters in postseason and preseason.

vaulters in posteason (Table 3 ).

Pole vaulters displayed better static balance in preseason compared to postseason time but this difference did not reach statistical significance (Figure 1a-d).

Coordination was also better but statistically insignificant in preseason compared to postseason (90.02\% and $86.50 \%$, respectively).

Soccer players exhibited lower balance scores in preseason compared to postseason, except sway area in ET1 (Figure 2a-d).

Student $t$-test showed statistically significant differences between posturographic parameters for mean total length $(p<0.01)$, path length in antero-posterior plane $(p<0.05)$, path length in medio-lateral plane $(p<0.01)$ in ET2. Moreover, mean total length $(p<0.05)$, path length in antero-posterior plane $(p<0.05)$, path length in medio-lateral plane $(p<0.01)$ in ET3 reached statistical significance. Coordination was better but statistically insignificant in preseason compared to postseason time (82.42\% and $82.02 \%$, respectively).

\section{Discussion}

The purpose of this study was to examine balance system of soccer players. Moreover, we compared standing balance of soccer players and pole vaulters. Our results point toward tendency for pole vaulters to exhibit better standing balance and visual-motor coordination. Although pole vaulters displayed superior static balance compared to soccer players, obtained data did not reveal any differences between groups of athletes both in preseason and postseason. Thereby the data from the posturography assessment did not support our hypothesis that pole vaulters have superior postural stability over soccer players. However, it is possible that the lack of statistically significant differences among pole vaulters and soccer players may result from the small number of participants.

As mentioned above, the pole vaulter must be good sprinter and gymnast as well, thus making pole vault a multiple tasks discipline. Cross-sectional studies revealed that gymnasts tended to have the best balance ability, followed by soccer players. However, it was found that gymnasts have superior dynamic bipedal balance but similar static balance to soccer players [3, 7]. Moreover, pole vaulters are trained in balance control similar to the gymnasts. They require heightened balance control to perform running with the pole, jumping, turning their body in midair and landing on the beam safely. However, 


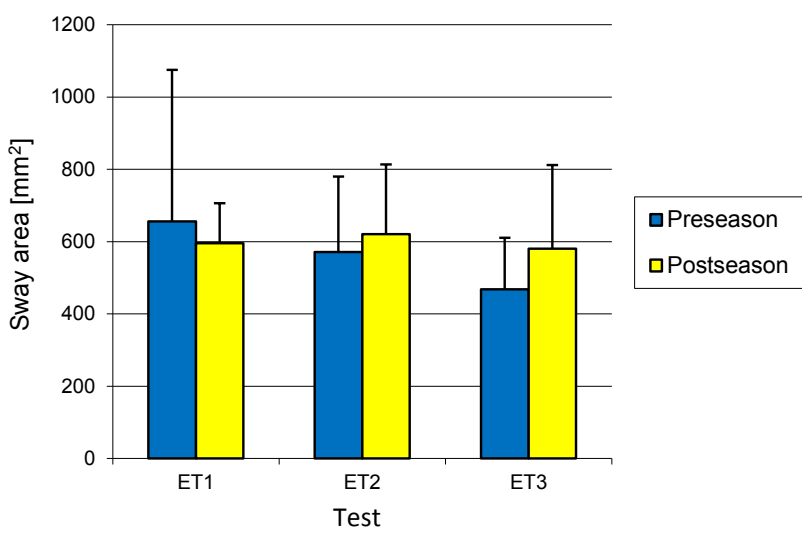

a

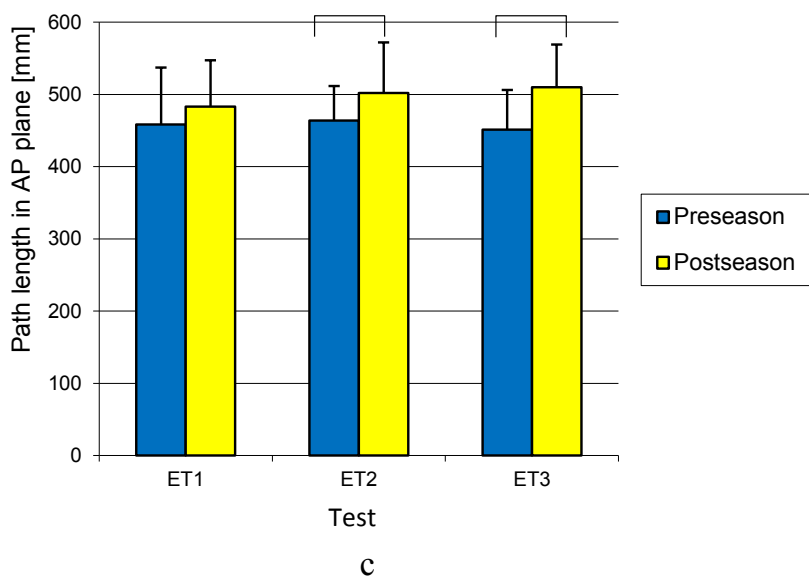

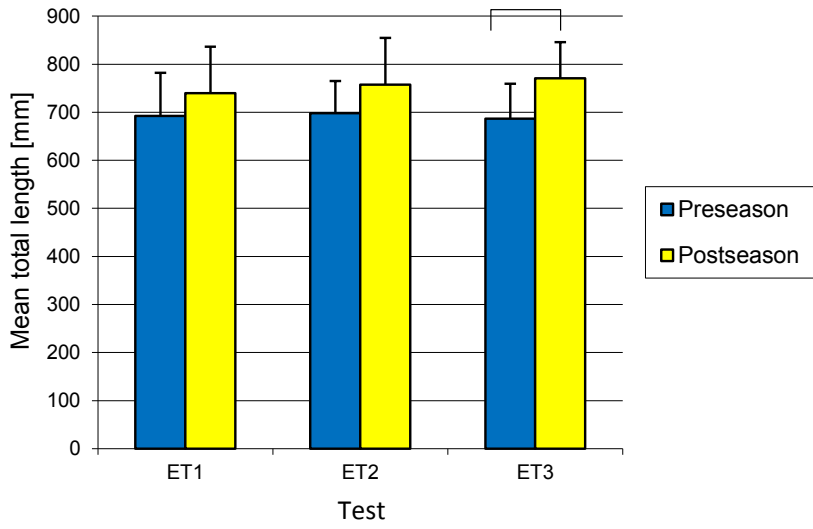

$\mathrm{b}$

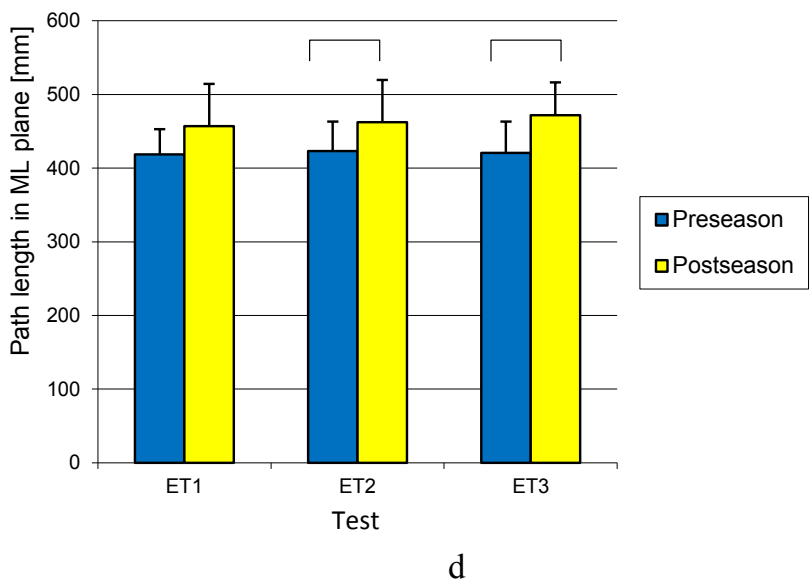

Figure 2. Group mean values ( \pm S.D.) of sway area, total length of stabilogram, length of stabilogram in sagittal plane and length of stabilogram in frontal plane in soccer players in postseason and preseason. Statistically significant differences are indicated with $* p<0.05, * * p<0.01$.

no study was found that compared the balance ability of sprinters with other athletes. Soccer players also practice balance training. This training may results in task-specific neural adaptations which may suppress spinal reflex excitability leading to less destabilizing movements and improved balance in athletes $[9,10]$.

Similar static balance in both examined groups may be the result of resistance training. Both pole vaulters and soccer players practice this type of training (also called strength training or weight training) to improve strength, anaerobic endurance and size of skeletal muscles. Pole vaulters practice weight training to make both trunk and legs muscles stronger, while soccer players are required to perform tasks causing greater strength of the lower extremities. Therefore the athletes of both groups are expected to have stronger muscles that are engaged in the upright position maintenance.

It is postulated that balance ability of athletes may be the result of repetitive experience that influences motor responses [11]. Others argue that superior balance is the result of training experience influencing a subject's ability to use sensory information such as proprioceptive and visual cues $[3,12]$. Training tasks repetition might also improve neuromuscular coordination, joint strength and joint range of motion that may enhance balance ability $[13,14]$. Bressel et al. suggested that both gymnasts and soccer players experience similar ground reaction forces for some skill manouvers [3]. Hence, it is possible that balance scores were similar among our examined groups of athletes. In addition, we observed superior visual-motor coordination of pole vaulters compared to the soccer players but statistical analysis did not reveal any differences between groups. Both groups of athletes usually perform static or dynamic balance and provide continuous visual stimuli to the balance system whereby the integration of visual input with motor output ensure a coordinated movement.

Movement patterns of pole vaulters and soccer players are dramatically different. Therefore, it is possible that functional balance tests might reveal differences in dynamic balance. It was proposed that gymnasts developed the ability in extracting and associating relevant sensory information for regulating posture since statistically significant superior dynamic balance differences in functional balance tests were observed [2]. On the other hand, some authors postulated that the excellent balance among high-level athletes is not the result of the greater activity of the vestibular system [11]. 
Our results showed that eyes closure resulted in the statistically insignificant increase of mean total length, path length in AP plane and path length in ML plane in both examined groups in preseason time. However, the tendency to reliance on visual information in both groups was observed suggesting the role of vision for maintaining better balance both in vaulters and footballers before regular season. Similar tendency was observed in postseason. Pole vaulters displayed statistically significant increased mean total length and path length in AP plane in closed eyes tests in postseason. It may suggest that vision is becoming increasingly important in pole vaulters from regular period to postseason. It is well-documented that the absence of vision disturbed postural control for judoists, gymnasts, ballet dancers and soccer players [15-18].

Pole vaulters displayed better static balance and visualmotor coordination in preseason compared postseason in open eyes test (ET1), except for sway area, closed eyes test (ET2) and coordination test (ET3), but these differences were statistically insignificant. Contrasting with pole vaulters, soccer players displayed statistically significant differences between preseason and postseason in closed eyes test (ET2) and coordination test (ET3) for mean total length $(L)$, path length in AP plane $\left(L_{A-P}\right)$ and path length in ML plane $\left(L_{M-L}\right)$. Superior static balance in preseason suggests that soccer players balance system is more efficient after the transition period when the frequency of training is decreased to three per week. In the transition period, the soccer players mainly perform individual exercises with the ball and short game between players of one team. Therefore, they are to lesser extent exposed to injuries and they have possibility to cure injuries acquired in midseason. During regular season game play often involves physical contact with other players including intentional pushing, or kicking. Moreover, the movement of soccer players is characterized by a great amount of sprinting, pivoting and sudden starts and stops. Therefore the most common site of injury in soccer player is the lower extremity. The most injured part of legs is joint. The most injured joint is the ankle joint, followed by the knee and the thigh [19]. Soccer is one of the sport that have the highest risk of damage to the anterior cruciate ligament (ACL) [20-23]. Such injury leads to knee joint instability and consequently to the development of early degenerative articular lesions. Some evidence in literature suggest that there are at least three mechanisms leading to the knee joint instability [24-30]. Although it deals with knee, these views may also apply to other joints. Firstly, injury to ACL leads to mechanical joint instability. Secondly, mechanical destruction of both mechanoreceptors and neuronal endings located in the ligaments leads to disruption of sensory pathways. Thirdly, erroneous action of unstable knee joint results in the altered reactions of sensory cells in other articular structures, whereby disordered information is transmitted to CNS. The result is incorrect perception of both posture and movements of the injured joint. It was even postulated that pre-injury movement characteristics can be different from non-injury movement characteristics.
Compared to non-injured players, the injured players have increased knee abduction angles at initial contact, maximum knee abduction angles, peak vertical ground reaction forces, side-to-side knee abduction movement differences and decreased maximum knee flexion angles before the damage to ACL [31]. Another study that prospectively identify risk factors for ACL injury revealed that the distance from center of mass to base of support and the angles between thigh and vertical axis were increased in ACL injury and that the angles trunk and vertical axis were decreased in ACL injury cases compared to noninjured control cases [32].

It is well-documented that mechanical and functional stability of both the knee joint $[33,34]$ and the ankle joint [35-38] plays important role in balance maintenance in the static balance tests. Therefore micro-trauma to the tendons and joints occurring over time may result in inferior static balance both in regular season and postseason in some soccer players. Our testing of posturographic parameters revealed high standard deviations in soccer players. This may be due to heterogeneity of soccer players group resulting from mini-injuries in some players. Injuries in the pole vaulters population are generally not traumatic in nature. A possible reason for this can be found in more precise control of where his/her lower extremities are positioned during and after the jump. Teitz postulated that the reason for the lack of ACL injuries in ballet was due to choreographed movement [39]. It is possible that, the frequency of injuries in pole vaulters is decreased due to both learnt and very precised movement.

\section{Conclusion}

We can conclude that pole vaulters and soccer players did not differ in terms of static balance but our results point toward an overall tendency for pole vaulters to exhibit better standing balance and visual-motor coordination compared soccer players. However, additional research carried out on a greater groups is required to compare balance system of pole vaulters and footballers. Suggestion for further research should include a comparison of pole vaulters, soccer players, other athletes and non-athletes in static and dynamic tests as well. In all mentioned groups static and dynamic balance should be examined to determine the most accurate indicator of postural stability.

The absence of visual information is linked to modify static balance in both examined group. For practical purpose, our results will be of benefit to the practitioners seeking the importance of vision in sport performance and trying to identify postural system efficiency. Coaches are recommended to use a variety of training program including both exercises with opened and closed eyes to improve balance.

Moreover, our findings allow us and coaches to evaluate the possible effects of training in preseason, midseason and postseason in athletes.

\section{Conflict of interest}

The authors declare no conflict of interest. 


\section{References}

1. Nashner LM. Practical biomechanics and physiology of balance. In: Jacobson GP, Newman CW, Kartush JM, editors. Handbook of Balance Function Testing. San Diego: Singular Publishing Group; 1997. P. 261-79.

2. Vuillerme N, Danion F, Marin L, Boyadjian A, Prieur JM, Weise I, et al. The effect of expertise in gymnastics on postural control. Neuroscience letters. 2001;303(2):83- 6. https://doi.org/10.1016/S0304-3940(01)01722-0

3. Bressel E, Yonker JC, Kras J, Heath EM. Comparison of static and dynamic balance in female collegiate soccer, basketball, and gymnastics athletes. J Athl Train. 2007;42(1):42-6.

4. Schmit JM, Regis DI, Riley MA. Dynamic patterns of postural sway in ballet dancers and track athletes. Exp Brain Res. 2005;163(3):370- 8. https://doi.org/10.1007/s00221-004-2185-6

5. Gerbino PG, Griffin ED, Zurakowski D. Comparison of standing balance between female collegiate dancers and soccer players. Gait \& posture. 2007;26(4):501- 7. https://doi.org/10.1016/j.gaitpost.2006.11.205

6. Cabri J, De Proft E, Dufour W, Clarys J. The relation between muscular strength and kick performance. In: Reilly $\mathrm{T}$, Lees A, Davids K, Murphy W, editors. Science and Football. London: E\&FN Spon; 1988. P. 186-93.

7. Davlin CD. Dynamic balance in high level athletes. Percept Mot Skills. 2004;98(3 Pt 2):1171- 6. https://doi.org/10.2466/pms.98.3c.1171-1176

8. Matsuda S, Demura S, Uchiyama M. Centre of pressure sway characteristics during static one-legged stance of athletes from different sports. J Sports Sci. 2008;26(7):775- 9. https://doi.org/10.1080/02640410701824099

9. Hrysomallis C. Balance ability and athletic performance. Sports Med. 2011;41(3):221- 32. https://doi.org/10.2165/11538560-000000000-00000

10. Taube W, Gruber M, Gollhofer A. Spinal and supraspinal adaptations associated with balance training and their functional relevance. Acta physiologica. 2008;193(2):101- 16. https://doi.org/10.1111/j.1748-1716.2008.01850.x

11.Balter SG, Stokroos RJ, Akkermans E, Kingma H. Habituation togalvanicvestibularstimulationforanalysisofposturalcontrol abilities in gymnasts. Neuroscience letters. 2004;366(1):71-5. https://doi.org/10.1016/j.neulet.2004.05.015

12.Ashton-Miller JA, Wojtys EM, Huston LJ, Fry-Welch D. Can proprioception really be improved by exercises? Knee Surgery, Sports Traumatology, Arthroscopy. 2001;9(3):128- 36. https://doi.org/10.1007/s001670100208

13.Lephart SM, Giraldo JL, Borsa PA, Fu FH. Knee joint proprioception: a comparison between female intercollegiate gymnasts and controls. Knee surgery, sports traumatology, arthroscopy, 1996;4(2):121- 4. https://doi.org/10.1007/BF01477265

14.Paterno MV, Myer GD, Ford KR, Hewett TE. Neuromuscular training improves single-limb stability in young female athletes. J Orthop Sports Phys Ther. 2004;34(6):305- 16. https://doi.org/10.2519/jospt.2004.34.6.305

15.HugelF, Cadopi M, KohlerF, Perrin P. Postural control of ballet dancers: a specific use of visual input for artistic purposes. International journal of sports medicine. 1999;20(2):86- 92. https://doi.org/10.1055/s-2007-971098

16.Paillard T, Costes-Salon C, Lafont C, Dupui P. Are there differences in postural regulation according to the level of competition in judoists? British journal of sports medicine. 2002;36(4):304- 5. https://doi.org/10.1136/bjsm.36.4.304

17.Perrin P, Deviterne D, Hugel F, Perrot C. Judo, better than dance, develops sensorimotor adaptabilities involved in balance control. Gait \& posture. 2002;15(2):187- 94. https://doi.org/10.1016/S0966-6362(01)00149-7

18.Barfield B, Fischman M. Control of a ground-level ball as a function of skill level and sight of the foot. Journal of Human Movment Studies. 1990;12:181-8.

19. Wong P, Hong Y. Soccer injury in the lower extremities. British journal of sports medicine. 2005;39(8):473- 82. https://doi.org/10.1136/bjsm.2004.015511

20.Metzl JD, Micheli LJ. Youth soccer: an epidemiologic perspective. Clin Sports Med. 1998;17(4):663-73. https://doi.org/10.1016/S0278-5919(05)70110-1

21.Dai B, Mao D, Garrett WE, Yu B. Anterior cruciate ligament injuries in soccer: Loading mechanisms, risk factors, and prevention programs. Journal of Sport and Health Science. 2014;3(4):299- 306. https://doi.org/10.1016/j.jshs.2014.06.002

22.Granan LP, Bahr R, Steindal K, Furnes O, Engebretsen L. Development of a national cruciate ligament surgery registry: the Norwegian National Knee Ligament Registry. Am J Sports Med. 2008;36(2):308- 15. https://doi.org/10.1177/0363546507308939

23. Gianotti SM, Marshall SW, Hume PA, Bunt L. Incidence of anterior cruciate ligament injury and other knee ligament injuries: a national population-based study. Journal of science and medicine, in sport. 2009;12(6):622- 7. https://doi.org/10.1016/j.jsams.2008.07.005

24.Ageberg E. Consequences of a ligament injury on neuromuscular function and relevance to rehabilitation - using the anterior cruciate ligament-injured knee as model. Journal of electromyography and kinesiology. 2002;12(3):205- 12. https://doi.org/10.1016/S1050-6411(02)00022-6

25.Chmielewski TL, Hurd WJ, Snyder-Mackler L. Elucidation of a potentially destabilizing control strategy in ACL deficient non-copers. Journal of Electromyography and Kinesiology, 2005;15:83-92. https://doi.org/10.1016/j.jelekin.2004.07.003

26.Krogsgaard MR, Dyhre-Poulsen P, FischerRasmussen T. Cruciate ligament reflexes. Journal of Electromyography and Kinesiology. 2002;12(3):177- 82. https://doi.org/10.1016/S1050-6411(02)00018-4

27. Noyes FR, Matthews DS, Mooar PA, Grood ES. The symptomatic anterior cruciate-deficient knee. Part II: the results of rehabilitation, activity modification, and counseling on functional disability. The Journal of bone and joint surgery, 1983;65(2):163- 74. https://doi.org/10.2106/00004623-198365020-00004

28. Noyes FR, Mooar PA, Matthews DS, Butler DL. The symptomatic anterior cruciate-deficient knee. Part I: the longterm functional disability in athletically active individuals. The Journal of bone and joint surgery, 1983;65(2):154- 62. https://doi.org/10.2106/00004623-198365020-00003

29.Reider B, Arcand MA, Diehl LH, Mroczek K, Abulencia A, Stroud CC, et al. Proprioception of the knee before and after anterior cruciate ligament reconstruction. Arthroscopy: The Journal of Arthroscopic \& Related Surgery, 2003;19:2-12. https://doi.org/10.1053/jars.2003.50006

30. Wojtys EM,HustonLJ.NeuromuscularPerformancein Normal and Anterior Cruciate Ligament-Deficient Lower Extremities. The American Journal of Sports Medicine. 1994;22(1):89-104. https://doi.org/10.1177/036354659402200116

31.Hewett TE, Myer GD, Ford KR, Heidt RS, Jr. , Colosimo AJ, McLean SG, et al. Biomechanical measures of neuromuscular control and valgus loading of the knee predict anterior cruciate ligament injury risk in female athletes: a 
prospective study. Am J Sports Med. 2005;33(4):492- 501. https://doi.org/10.1177/0363546504269591

32.Sheehan FT, Sipprell WH, 3rd, Boden BP. Dynamic sagittal plane trunk control during anterior cruciate ligament injury. Am J Sports Med. 2012;40(5):1068- 74. https://doi.org/10.1177/0363546512437850

33.Zatterstrom R, Friden T, Lindstrand A, Moritz U. The effect of physiotherapy on standing balance in chronic anterior cruciate ligament insufficiency. Am J Sports Med. 1994;22(4):531- 6. https://doi.org/10.1177/036354659402200416

34.Hassan BS, Mockett S, Doherty M. Static postural sway, proprioception, and maximal voluntary quadriceps contraction in patients with knee osteoarthritis and normal control subjects. Annals of the rheumatic diseases. 2001;60(6):612-8. https://doi.org/10.1136/ard.60.6.612

35.Gauffin H, Tropp H, Odenrick P. Effect of ankle disk training on postural control in patients with functional instability of the ankle joint. International journal of sports medicine. 1988;9(2):141- 4. https://doi.org/10.1055/s-2007-1024996

36. Hertel J, Olmsted-Kramer LC. Deficits in time-toboundary measures of postural control with chronic ankle instability. Gait \& posture. 2007;25(1):33- 9. https://doi.org/10.1016/j.gaitpost.2005.12.009

37.Tropp H, Odenrick P, Gillquist J. Stabilometry Recordings in Functional and Mechanical Instability of the Ankle Joint. International journal of sports medicine. 1985;06(03):180- 2. https://doi.org/10.1055/s-2008-1025836

38.Konradsen L, Ravn JB. Prolonged peroneal reaction time in ankle instability. International journal of sports medicine. 1991;12(3):290- 2. https://doi.org/10.1055/s-2007-1024683

39.Teitz C. Hip and Knee Injuries in Dancers. Journal of Dance Medicine \& Science. 2000;4(1):23029.

\section{Information about the authors:}

Katarzyna Dmitruk; (Corresponding Author); http://orcid.org/0000-0002-1925-345X; Katarzyna_dmitruk@cm.umk.pl; Department of Physiology, Collegium Medicum in Bydgoszcz, Nicolaus Copernicus University in Toruń, Poland; Bydgoszcz Poland.

Małgorzata Gałązka; http://orcid.org/0000-0002-0471-2481; Malgorzata.galazka@cm.umk.pl; Department of Physiology, Collegium Medicum in Bydgoszcz, Nicolaus Copernicus University in Toruń, Poland; Bydgoszcz Poland.

Mirosława Cieślicka; http://orcid.org/0000-0002-0407-2592; m.cieslicka@cm.umk.pl; Department of Physiology, Collegium Medicum in Bydgoszcz, Nicolaus Copernicus University in Toruń, Poland; Bydgoszcz Poland.

Dariusz Soszyński; http://orcid.org/0000-0002-0178-9635; dareks@cm.umk.pl; Department of Physiology, Collegium Medicum in Bydgoszcz, Nicolaus Copernicus University in Toruń, Poland; Bydgoszcz, Opole Poland.

Robert Stępniak; http://orcid.org/0000-0002-0165-0190; Robi1969@wp.pl; Institute of Individual Sports, Kazimierz Wielki University in Bydgoszcz, Poland; Bydgoszcz Poland.

Mariusz Klimczyk; http://orcid.org/0000-0003-4672-6344; Klimczyk_mariusz@ukw.edu.pl; Institute of Individual Sports, Kazimierz Wielki University in Bydgoszcz, Poland; Bydgoszcz Poland.

Sergii S. lermakov; http://orcid.org/0000-0002-5039-4517; sportart@gmail.com; Gdansk University of Physical Education and Sport; Kazimierza Górskiego 1, 80-336 Gdańsk, Poland.

Cite this article as:

Katarzyna Dmitruk, Małgorzata Gałązka, Mirosława Cieślicka, Dariusz Soszyński, Robert Stępniak, Mariusz Klimczyk, Sergii S. lermakov. Comparison of the standing balance between pole vaulters and soccer players in preseason and postseason.

Physical education of students, 2020;24(2):92-99.

https://doi.org/10.15561/20755279.2020.0204

This is an Open Access article distributed under the terms of the Creative Commons Attribution License, which permits unrestricted use, distribution, and reproduction in any medium, provided the original work is properly cited http://creativecommons.org/licenses/by/4.0/deed.en

Received: 08.02.2020

Accepted: 15.03.2020; Published: 30.04.2020 